\title{
Digital Image Denoising Techniques in Wavelet Domain with another Filter: A review
}

\author{
${ }^{1}$ Barwar Mela Ferzo, ${ }^{2}$ Firas Mahmood Mustafa \\ ${ }^{1}$ Department of IT, Duhok Polytechnic University, Duhok, Kurdistan of Iraq \\ ${ }^{2}$ Department of Communication, Nawroz University and (Duhok Polytechnic University), Duhok, Kurdistan Region \\ of Iraq
}

\begin{abstract}
Image denoising is a challenging issue found in diverse image processing and computer vision problems. There are various existing methods investigated to denoising image. The essential characteristic of a successful model that denoising image is that it should eliminate noise as far as possible and edges preserving and necessary image information by improving visual quality. This paper presents a review of some significant work in the field of image denoising based on that the denoising methods can be roughly classified as spatial domain methods, transform domain methods, or can mix both to get the advantages of them. This work tried to focus on this mixing between using wavelet transform and the filters in spatial domain to show spatial domain. There have been numerous published algorithms, and each approach has its assumptions, advantages, and limitations depending on the various merits and noise. An analyzing study has been performed comparative in their methods to achieve the denoising algorithms, filtering approach and wavelet-based approach. Standard measurement parameters have been used to compute results in some studies to evaluate techniques while other methods applied new measurement parameters to evaluate the denoising techniques.

Keywords: Image Denoising, Discrete Wavelet Transform (DWT), Complex Wavelet Transform, Wiener Filter (WF), Median Filter (MF).
\end{abstract}

\section{Introduction}

${ }^{1}$ In an increasingly digital world, Digital Images play an essential role in the day to day applications such as Digital Cameras, Magnetic Resonance Imaging, and Satellite TV as well as in fields of research and technology including Geographical Information System. Overall, datasets obtained by noise polluted image sensors. Images often corrupted with noise throughout the acquisition, transmission, the retrieval from storage media, and interfering with natural phenomena, and this noise can damage the data of interest. The noise is considered to be the most critical problem because it corrupts the image due to blurring,

Academic Journal of Nawroz University

(AJNU) Volume 9, No 1 (2020).

Regular research paper : Published 4 March 2020

Corresponding author's e-mail : barwar.mela@gmail.com Copyright (C2018 ${ }^{1}$ Barwar Mela Ferzo, ${ }^{2}$ Dr. Firas Mahmood Mustafa. This is an open access article distributed under the Creative Commons Attribution License. movement, camera misfocus, etc. The images are affected by different types of noise, such as salt and pepper noise, additive noise, speckle noise, etc. [1].

The noisy image leads to confusion of the image and loss of its features so, the noise considered as a significant factor in degrading the image quality; thus noise reduction is an essential technology in image analysis and the first step to be taken before images are analyzed [2, 3]. Therefore, Image Denoising techniques are required to prevent image contamination of this form of noise [4]. Image denoising re-processing is a significant function before images further processed like texture analysis, segmentation, feature extraction, etc. [5]. Over the years, several denoising approaches have been proposed, such as wavelet transform, linear filters, non- linear filters (mean, median, bilateral, and wiener filter) Have been used to eliminate noise from 
images, but these traditionally filters may result in some problems, such as blurring sharp edges, destroying lines and other fine image details, and fail to effectively remove heavy-tailed noise data [6], while it is well known that wavelet transform is a signal processing technique which can display the signals on in both time and frequency domain.

Wavelet transform is a superior approach to improve the quality of images due to its multi-resolution and subbands property and provides signals to localize in frequency and time domain [7]. Donoho's suggested wavelet thresholding as a signal estimation technique that takes advantage of wavelet transformation capabilities to denoising signal. This technique reduces noise by destroying insignificant coefficients relative to a certain threshold and turns out to be efficient and straightforward. These coefficients subbands processed via hard or soft thresholding. The hard thresholding eliminates (sets to zero) coefficients that are smaller than a threshold; the soft thresholding shrinks the coefficients that are larger than the threshold as well. The effectiveness of thresholding for denoising image depends on the selection of a suitable threshold such as VisuShrink, BayesShrink, SureShrink, etc. [8].

Several researchers have shown that apply the only wavelet transform on the image is insufficient to obtain an integrated noise-free image and image stay blurring. Hybrid algorithm of WT with liner filter and non-linear filter applied on noisy image to filtering image noise out while the edges of the image are well preserved. WT is integrating with a filter to solve the problem of unsharpened edges and poor quality of background during the removal of blurriness of image [9]. Wavelet denoising technique eliminates image details and produces smooth image sharpness. So, there is a need of such filter in image denoising to filtering noise without affecting essential image characteristics [10].
Also to remove mixed noise and produce a right quality image with loss of as small as a possible value of information of the image during denoising process [1114].

This review paper provides different methodologies for noise reduction depending on wavelet transform and various filters. It also gives us insights into the approaches by which the reliable method is to be concluded and estimated an approximation of the original image from the noisy image. The rest of the paper organized as follows: Wavelet-based threshold is mentioned briefly in section one. A broad study of the literature review shown in section 2. Conclusion and Discussion presented in section 3.

\section{Image Denoising Problem Statement}

The problem of image denoising can be modeled mathematically as follows:

$$
\mathrm{Y}=\mathrm{X}+\mathrm{z}
$$

Where:

$Y:$ is the noisy image.

$X:$ is the unknown clean image (denoised image).

$\mathrm{z} \quad$ : is represents additive white Gaussian noise (AWGN) with standard deviation $\sigma_{n}$.

The noise $\mathrm{z}$ can be estimated in practical applications by various methods, such as robust median estimator and other methods.

The aim of the denoising process is to rebate the noise in the images while minimizing the loss of original features and increasing the signal-to-noise ratio (SNR). The significant challenges for image denoising are as follows [15]:

- Flat areas should be smooth.

- Edges should be protected without blurring.

- Textures should be preserved.

- New artifacts should not be generated.

Owing to solve the clean image $X$ from the Eq. (1) is an ill-posed problem, we cannot get the unique solution 
from the image model with noise. To obtain a good estimation image, image denoising has been wellstudied in the field of image processing over the past several years. Generally, image denoising methods can be roughly classified as spatial domain methods, transform domain methods, or can mix both to get the advantages of them. This work tried to focus on this mixing [15].

\section{Wavelet Based Thresholding}

Wavelet thresholding is a signal estimation strategy that takes advantage of Wavelet transform capabilities to denoising signal. This strategy reduces noise by destroying insignificant coefficients relative to a certain threshold and turns out to be efficient and straightforward, depends heavily determines the value of the threshold parameter and the choice of this threshold, to a great extent the efficiency of denoising. There are several studies on thresholding the Wavelet coefficients [16]. Wavelet denoising removes the noise in the signal while preserving the characteristics of the signal regardless of its frequency signification. There are three steps involved as a linear forward wavelet transform, a nonlinear thresholding step, and a linear inverse wavelet transform. The process, commonly called denoising by using 2D-Wavelet Transform, consists of the following main stages, which shown in figure 1 . The first stage is to apply the $2 \mathrm{D}$ discrete wavelet transformation to the input image (noisy image), while the second stage is to calculate the threshold values and how to apply each value with its related sub band to generate a new and clear sub band, whereas the third stage is about to reconstruct the denoised image (The output) by using the 2D inverse wavelet transformation with the new clear sub bands.

\section{Wavelet Domain and Filtering Denoising Methods}

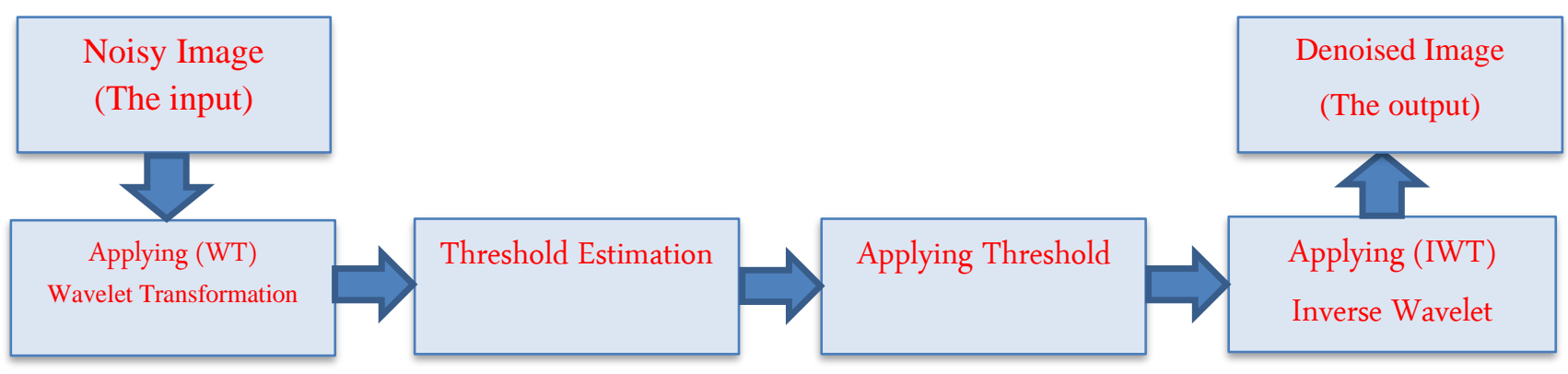

Fig (1): The Block diagram of Image denoising using 2D-Wavelet Transform.

In contrast with spatial domain filtering methods, Wavelet transforms domain filtering methods first transform the given noisy image to another domain. Then they apply a denoising procedure on the reconstructed image according to the different characteristics of the image and its noise (larger coefficients denote the high-frequency part, i.e., the details or edges of the image, smaller coefficients denote the noise). To increase the efficiency of the denoising methods, many works have been implemented in this field by mixing the wavelet transform domain filtering besides the spatial domain filtering methods, some of these works will be illustrated and evaluated as follows:

[17] proposed an adaptive wavelet filter for image denoising. In their suggested method, a real-world remote sensing image dataset built from AGRI on FengYun-4An and a learning adaptive wavelet filter 
(LAWF) was suggested to reduce the variable stripe noise caused by different SRF. The proposed algorithm suggested a new measurement parameter to determine the appropriate adaptive filter coefficients termed Weight Sum Variance of Digital Number Probability (WSVODP). Also, new measurement parameters are used to measure the denoising image, which is harshness information with separated direction (HISD) to demonstrates details of the image instead of traditional measurement coefficients such as (PSNR), Normalized mean square error (NMSE), average gradient value of the image (AGVI). Experimental results of the presented approach illustrate that the algorithm could effectively reduce the variable stripe noise from different observation targets, and it was prevented ringing artifacts to edge compensation approach, which was equipped by the AGRI scanning model. Therefore, the proposed algorithm is useful in reducing variable stripe noise where applied on cloud detection image.

[18] investigated a new algorithm based on adaptive median filtering and wavelet threshold function (AMF-WT) to adjust the template size adaptively according to the noise concentration. In their study adaptive median filtering used to denoising image from salt-and-pepper noise, while two-level decomposition is done on the image noisy by wavelet to denoising the high-frequency coefficients with improved the threshold function then reconstructed with low-frequency coefficients. The performance proposed method PSNR measurement parameter is associated. The experimental result shows that the investigated algorithm is superior to the adaptive median filter and median filter in eliminating salt-andpepper noise and can retain more image details and edge information. The improved threshold function designed has a better denoising effect than a hard threshold function and soft threshold function.

[19] suggested a new method to enhance visual quality and effectively eliminate speckle noise of the image using Speckle Reducing Anisotropic Diffusion (SRAD) filter combination with the discrete wavelet transform by selection Bayesian threshold technique. In their proposed method, the uncompressed noisy image has processed by SRAD filter, then logarithmic transformation (log) is performed on the filtered image to convert speckle noise to Gaussian noise. Finally, the DWT using Bayesian thresholding has been done on the log compressed image to obtain a denoising image. The performance of the proposed algorithm compared with the other existing methods during some measurement parameters such as PSNR, RMSE, SSIM, and computational time (s) metrics. Experimental results show that the proposed method somewhat demonstrates the better visual quality of the reconstructed image by making a proper equalization in speckle-noise reduction and preservation of edges.

[20] Presented a combined method based on the improved wavelet threshold function and median filtering. In this study, the detail coefficients (highfrequency) mixed with Gaussian noise are denoised after the wavelet decomposing of the image. After reconstructing the wavelet coefficients, two times of median filtering is performed for the reconstructed images to obtain the denoised image. The proposed method denoised the image under the condition of measurement parameter such as PSNR. The experimental results of proposed algorithm show that the denoising effect of the improved threshold function is superior to hard threshold and soft threshold, therefore presented method can effectively remove the mixed noise in the image, such as Gaussian noise, salt-and-pepper noise and speckle noise, it has a strong adaptability, a stable denoising 
effect and can be applied in practical engineering image denoising.

[21] suggested denoising image approach basic on discrete wavelet transform using Soft Thresholding and Wiener Filter. In their proposed method, Wiener Filter applied on the Approximation coefficient and Soft Thresholding performed on the Detail coefficients based on $\mathrm{db} 4$ wavelet. The performance of the presented algorithm evaluated in terms of PSNR and MSE. Competitive performance compared to other methods has been observed. The value of measurement parameters such as PSNR and MSE for denoising image of the proposed method compared with the noisy images which contain AWGN and salt \& pepper noise.

[22] proposed a novel method for speckle noise reduction of time series SAR images based on wavelet transform and Kalman filter to preserve the spatial resolution, and reduce the time of processing in the field of remote sensing. In their study, biorthogonal spline wavelet and Birge-Massart strategy were chosen to obtain denoising thresholds. While two assessment parameters used which are Equivalent Number of Looks (ENL) and Edge-Enhancing Index (EEI) parameters to evaluate the capability of the proposed method to reduce the speckle noise and its effectiveness to preserving the edge structures. The experimental results of proposed algorithm show that the method has efficient performance compared to another method for speckle reduction of time series SAR images in the terms of smoothing homogeneous areas and preserving edges and details and also can preserve the major edge structures and the spatial resolution while reducing the speckle noise from time series SAR images.

[23] proposed a combination algorithm of speckle reducing anisotropic diffusion (SRAD), soft thresholding and a guided filter to effectively remove speckle noise from SAR images while preserving edge information. In their suggested technique an SRAD filter used as preprocessing filter to preserve the useful information in the image of noisy images, a logarithmic transformation ( $\mathrm{Log}$ ) is applied to convert speckle noise are remaining in the filtered image into additive noise, while guided filter and soft thresholding were used to remove the noise in the approximation sub-image (high-frequency, lowfrequency). The performance of the proposed algorithm and the conventional noise reduction methods are compared using the quantitative values of parameters RMSE, an equivalent number of looks (ENL), PSNR and SSIM. The experimental results indicate that the proposed algorithm shows the best performance regarding speckle noise removal and edge preservation in SAR images compared to conventional filtering methods.

[24] suggested a new approach to denoising highly distorted images affected by speckle noise. This proposed approach is carried out in a homomorphic framework using bacterial foraging optimization (BFO) cascaded with wavelet transformation and wiener filter. In their proposed method, the wavelet packet decomposition is used to identify and remove the noise from affected pixels. For pre-processing purposes, the Wiener filter used. The BFO algorithm is used to reduce the amount of error between the speckled image and the not speckled output image from the homomorphic framework after processing. The multiplicative noise (speckle) was transformed into the additive form by log transformation of the original image. PSNR and MAE are two measurement criteria used in the proposed method of quality evaluation of the image. The simulation result of the proposed approach shows that the combination of 
DWT and wiener filter performs best results in the form of information preservation of the image by removing noise from images, while the combine $\mathrm{BFO}$ and AMF achieve superior visual and statistical results.

[25] presented a modified technique that based on dual-tree complex wavelet transform and interpolation. In their proposed method, DTCWT cascaded structure used to generate different frequency bands for analysis, while denoising approach for the image is used based on dual-tree complex wavelet and wiener filter technique. Proposed method focused on the enhancement of the resolution of a low-resolution medical image, the Low Resolution (LR) of input images decomposed into different frequency sub-bands using six decomposition levels. Different quality measurement criteria such as PSNR, SSIM, and MSE are used to assess resolution enhancement proposed technique and to determine the quality of denoised images. Findings show that the proposed approach has a better smoothness and accuracy balance of image than the DWT and is less redundant than the SWT.

[26] investigated a new denoising image algorithm using a double-density dual-tree complex wavelet transform (DDCWT) based on a modified threshold function for Computed Tomography (CT) image. In their proposed study they decomposed the noisy image into high frequency and low-frequency components during DDCWT while the adjusted threshold used for DDCWT coefficient in the next step and as usual, it was rebuilt image by reconstructing high frequency and low-frequency components through the inverse decomposition of DDCWT. Hard threshold function selected with the chosen universal threshold to denoising $\mathrm{CT}$ images. For assessing the effectiveness of the proposed method, two measurement parameters computed visual quality between the original image and the denoised image, which are (PSNR) and (MSE). The experimental result illustrates that the presented approach has more effective and efficient than the DTCWT to maintain more rich details in images.

[27] investigated a hybrid image denoising algorithm based on wiener filter is to remove the additive white Gaussian noise (AWGN). They develop an image denoising algorithm based on wiener filter and its method noise thresholding using discrete wavelet transform to deal with edges and details in images more efficiently. The performance of the proposed method compared with Standard Median Filter (SMF), Relaxed Median Filter (RMF), FPDEF and Bilateral Filter $(\mathrm{BF})$, while the filtered images are evaluated using quantitative measures Root Mean Square Error (RMSE), PSNR \& Image Quality Index (QI) to measure image efficiency. Experimental results of the proposed algorithm indicate achieves much better performance in removing the additive white Gaussian noise from the image with minimum edge blurring compared to other filters.

[28] presented a hybrid filter that combines the Modified Median Wiener filter (MMWF) and Absolute Difference and Mean filter (ADMF). The MMWF filter merged the complementary qualities and abilities of the Median (MF) and Wiener Filter (WF). To improve the quality of the image, the proposed method suppressed the Gaussian noise in Computer Tomography (CT) medical images for better disease diagnosing. This hybrid proposed algorithm performance compared with similar techniques depending on two commonly measured in terms of (PSNR) and (MSE). The simulation result shows that the hybrid suggested technique article is best suited for removing Gaussian noise in CT images modality. 
[29] suggested a new method of image denoising based on using median filter (MF) in the wavelet domain. The hybrid proposed algorithm depended on to apply the DWT only or the median filter only and mixing between them on a noisy image. In their suggestion a spatial filter which is median filter used to remove Gaussian noise from noisy scaled image to blurring and smoothing edges and details, while the wavelet transform applied to analyze the image, WT working on the frequencies of sub-bands split from an image. The denoising images are evaluated depending on two measurement parameters which are MSE and PSNR. The simulation result of the proposed approach shows that the combination of DWT and Median filter performs significant effects and can recover much more detail of the original image.

[30] suggested a new denoising algorithm to restore the image corrupted by Gaussian noise based on the bilateral filter and its method noise thresholding based on the dual-tree complex wavelet transform. In this proposed technique the bilateral filter removes the noise as well as some details of the image, so these details are estimated accurately in the wavelet domain with MMSE so that the edges and other features of the original image are preserved properly, while the sum of the bilateral filter output and the detail image will give the final denoised image. BayesShrink has been used in this proposed method as a selection of threshold technique to compute each sub-band level in the wavelet decomposition, while PSNR, SSIM, and UIQI index values used as measurement parameters to performance proposed method depending on denoising image. Experimental results show that the proposed algorithm is superior compared to another filter algorithm in terms of visual quality which is improved significantly as the accuracy of the wavelet decomposition and perfect reconstruction of the image with preserve essential details of an image such as edges, textures, etc.

[31] proposed a new technique based on the Wiener filter with a high-resolution estimate that will evaluate the signal power while preserving the edge details. Basic on their proposed method, the local covariance is used to get high-resolution coefficients from coefficients with low resolution while to estimate the signal variance in the wiener filter the high-resolution values used. The results are quantitatively analyzed using Peak Signal-to-Noise Ratio (PSNR). Experimental results indicate that the proposed algorithm substantially improves objective and subjective output; consequently, the proposed method activated the reduction of image noise while edge details preserving. In contrast with other approaches, the denoising image details have provided better visual quality.

[32] proposed a new method for image denoising. The proposed method based on a combination of DWT and MF. In their recommended way, the WT analyzes the image because it can split the image into sub-bands and function separately on each sub-band frequency. Also, the noise ratio at the noisy image estimated by a robust median estimator parameter. Two measurement parameters are used to determine the noise in the image, which is (MSE) and (PSNR) to evaluate the proposed image denoising method. Experimental results of the submitted method show efficiency denoising images and obtained the best results for image denoising process by using different types of wavelet transform filters.

[33] proposed a scheme based on Wiener filtering in the wavelet domain. In the proposed system, the CT image is denoised using the concept of Wiener filtering and method noise in the wavelet domain. The concept of their proposed technique presents that the 
edge extraction improves the quality of denoised CT images through discrete wavelet transformation (DWT) concerning noise suppression and preservation of the structure. With the motivation of combining two methods, wiener filtering and thresholding in the wavelet domain are performed using the concept of method noise. To measure the performance of the suggested way, the performance metrics (PSNR, SSIM) used. The resultant image of the proposed methodology gives noise suppressed as well as edge preserved image. The experimental result of the proposed method indicates that the quality of $\mathrm{CT}$ images enhanced in terms of noise reduction as well as structure preservation. Therefore, the small image details preservation and no visual artifacts created. The performance of the proposed algorithm has excellent potential to serve for denoising the computed tomography images.

[34] investigated a novel wiener filtering and adaptive soft thresholding of wavelet transform coefficients, which are a combination of spatial and frequency domain techniques for removing speckle noise. The algorithm uses a Wiener filter as a preprocessing stage in the spatial domain, and adaptive soft thresholding of Wavelet transform coefficients in the frequency domain. In their proposed algorithm, the threshold at each sub band is calculated automatically from the variance (standard deviation) of the subbands. Twolevel decomposition of the wavelet transform is considered, and thresholding is applied only to detail coefficients. Results compared in terms of Parameters PSNR, and MSE. Experimental results presented that the proposed method is efficient in removing speckle noise compared to other algorithms.

[35] proposed algorithm is based on wavelet transform that denoised the noisy image by adding weighted high pass filtering coefficients (WHFC) in the wavelet domain. They implemented a smart system for estimating the iterative noise variance, which denoised the noisy image. They are applying WHFC on the detailed parts to increased intensity of the pixels. Then, they convolved WHFC with detailed coefficients of wavelet. The resultant image was obtained during the inverse wavelet transform process, while the resulting image is visually blurred. Adaptive Wiener filter used to minimize the blurriness of the ensuing image depending to achieve the maximum PSNR. The experimental result shows that this method is perfect for noise reduction gives higher PSNR and better visual quality of the image.

[36] Proposed a denoising approach basing on dualtree complex wavelet and shrinkage with the Wiener filter technique applied for medical images. In this study, denoising methods using the universal threshold technique used to select the threshold value. They estimate the noise level while hard and soft thresholding functions are used to shrink wavelet coefficients and compare the efficiency of denoising images based on Peak Signal to Noise Ratio (PSNR) and Structural Similarity Index Measure (SSIM) to evaluate the proposed technique. The findings of the proposed method show that the denoising images have a better balance of smoothness and accuracy than the DWT and are less redundant than the Stationary Wavelet Transformation (SWT).

[13] presented a Hybrid filter is it composite of various filters to remove a mixed type of noise from a digital image, a combination of three filters median filter, wiener filter, and bilateral filter. In their proposed algorithm five types of method applied on noisy image to get denoising image depending on the performance of some parameters such as MSE, signal to noise ratio (SNR), PSNR, RMSE, and SSIM. The experimental result shows that the proposed method can recover 
much more detail of the original image and provides a successful way of image denoising compared with another process in the study.

The summary of the selected researches that deals with the image denoising by the using Wavelet transformation with a spatial domain filter are shown in Table (1) below.

\section{Discussion}

Many factors play a critical role to obtain denoising image entirely, such as the threshold and parameter, the type of noise and field of the image also have an active role in eliminating noise. All these characteristics must be considered to evaluate the performance of the proposed technologies. By reviewing and assessing the proposed and implemented methods of work covered in this research, the following points can set:

- Many research focused on medical images (Computerized Tomography (CT), Ultrasound and X-ray) and another focused on earth science image (Synthetic Aperture Radar (SAR)) while other methods focused on standard image (Lena, Cameraman, kid, etc.) to remove noise in noisy image depends on the field in which the image used in it.

- Numerous measurement parameters are computed to evaluate technique depending on the value of denoising image compared with noisy image, some of them are new and others are the tradition.

- The selection of the filter is playing a critical role in the denoising methods. Also, the choice of the filter must be compatible with the type of noise, for example, the performance of Median filter to denoise Salt \& Pepper noise is better than other filters, while the performance of the Wiener Filter to denoise Speckle and Gaussian noise is better than Median filter and others filter and so on.

- There are several types of noises exist in the image at the same time, so many works focused on the noisy image that contents mixed noise, to remove mixed noise which exists in the image. Therefore, denoising image with one type of filter inefficient to remove noise, while the combined denoising method with various filters is needed to be more efficient to eliminate the mixed noisy image as possible.

- Numerous studies focused on the template of the noisy image (window size) to denoising image while others concentrate on the edges details and critical features of the noisy image.

- Many techniques developed a simple method to remove noise concerning the time of processing to get a denoising image, while others developed complex methods such as DTDWT using a parallel combination of two DWTs to obtain denoising image which achieved an effective result. Still, there is a lack of image details and take long processing time.

- Some research has used new measurement parameters such as WSVODP, which is not suitable for all types of images, especially CT images, while EEI, ENL parameters suitable for SAR images. 
Table (1): The summary of the selected researches that deals with the image denoising by the using Wavelet transformation with a spatial domain filter.

\begin{tabular}{|c|c|c|c|c|c|c|c|}
\hline $\begin{array}{l}\text { Authors and } \\
\text { year of } \\
\text { Publication }\end{array}$ & $\begin{array}{l}\text { Problem } \\
\text { Domain }\end{array}$ & $\begin{array}{c}\text { Type of } \\
\text { noise }\end{array}$ & $\begin{array}{l}\text { Denoising } \\
\text { Filtering } \\
\text { Techniques }\end{array}$ & Advantages & Disadvantages & $\begin{array}{c}\text { measuremen } \\
\text { t parameter } \\
\text { to } \\
\text { performance } \\
\text { proposed } \\
\text { method }\end{array}$ & Short description \\
\hline $\begin{array}{l}\text { (Chen et al. } \\
\text { 2019) [17] }\end{array}$ & \begin{tabular}{|l} 
Variable \\
stripe noise \\
in the water \\
vapor band \\
remote \\
sensing \\
images of \\
the AGRI \\
affects \\
many \\
application \\
s when one \\
full disk \\
image is \\
separated \\
into ten \\
sub-images \\
for \\
transformin \\
g as soon as \\
possible.
\end{tabular} & $\begin{array}{l}\text { variable } \\
\text { stripe } \\
\text { noise }\end{array}$ & $\begin{array}{l}\text { Adaptive } \\
\text { Wavelet } \\
\text { Filter }\end{array}$ & $\begin{array}{l}\text { reduce the } \\
\text { variable stripe } \\
\text { noise caused } \\
\text { by different } \\
\text { SRF }\end{array}$ & $\begin{array}{l}\text { Used for specific } \\
\text { purpose which is } \\
\text { Advanced } \\
\text { Geostationary } \\
\text { Radiation Imager } \\
(\text { AGRI) }\end{array}$ & $\begin{array}{l}\text { WSVODP,HIS } \\
\text { D }\end{array}$ & $\begin{array}{l}\text { Introduces a new } \\
\text { parameter termed } \\
\text { weight sum } \\
\text { variance of digital } \\
\text { number probability } \\
\text { (WSVODP), which } \\
\text { is used to indicate } \\
\text { the appropriate } \\
\text { wavelet filter } \\
\text { coefficients. }\end{array}$ \\
\hline $\begin{array}{l}\text { (Qian 2019) } \\
{[18]}\end{array}$ & $\begin{array}{l}\text { Hard } \\
\text { threshold } \\
\text { and soft } \\
\text { threshold } \\
\text { has } \\
\text { effecting } \\
\text { in image } \\
\text { as } \\
\text { oscillation } \\
\text { and } \\
\text { boundary } \\
\text { blurring. }\end{array}$ & $\begin{array}{l}\text { salt-and- } \\
\text { pepper }\end{array}$ & $\begin{array}{l}\text { Adaptive } \\
\text { Median } \\
\text { Filtering } \\
\text { and } \\
\text { Wavelet } \\
\text { Threshold } \\
\text { function } \\
(\text { AMF-WT) }\end{array}$ & $\begin{array}{l}\text { maximum } \\
\text { template can } \\
\text { avoid losing } \\
\text { more image } \\
\text { details and } \\
\text { edge } \\
\text { information } \\
\text { when the } \\
\text { noise } \\
\text { concentratio } \\
\text { n is very } \\
\text { high, and the } \\
\text { remaining } \\
\text { noise is } \\
\text { eliminated } \\
\text { by wavelet } \\
\text { threshold } \\
\text { function }\end{array}$ & $\begin{array}{l}\text { Maximum } \\
\text { template which } \\
\text { is set very large } \\
\text { effected, the } \\
\text { details and } \\
\text { edges of the } \\
\text { denoised mage } \\
\text { cannot be } \\
\text { preserve well. }\end{array}$ & PSNR & $\begin{array}{l}\text { Improve } \\
\text { threshold } \\
\text { function which } \\
\text { has better } \\
\text { denoising effect } \\
\text { than hard } \\
\text { threshold } \\
\text { function and soft } \\
\text { threshold } \\
\text { function. }\end{array}$ \\
\hline
\end{tabular}




\begin{tabular}{|c|c|c|c|c|c|c|c|}
\hline $\begin{array}{l}(\underline{\text { Nishu et al. }} \\
\text { 2019) [19] }\end{array}$ & \begin{tabular}{|l|} 
obtain \\
better \\
visual \\
quality of \\
the \\
speckle \\
noise \\
reduction \\
and edge \\
preservatio \\
n
\end{tabular} & $\begin{array}{l}\text { speckle } \\
\text { noise }\end{array}$ & $\begin{array}{l}\text { Speckle } \\
\text { Reducing } \\
\text { Anisotropic } \\
\text { Diffusion } \\
\text { (SRAD) in } \\
\text { combination } \\
\text { with } \\
\text { the Discrete } \\
\text { Wavelet } \\
\text { Transform } \\
\text { (DWT) using } \\
\text { Bayesian } \\
\text { Threshold }\end{array}$ & \begin{tabular}{|l} 
Remove \\
difficult form \\
of noise which \\
is speckle \\
noise to obtain \\
better visual \\
quality of the \\
reconstructed \\
image by \\
asking a good \\
equalization in \\
speckle noise \\
reduction and \\
preserve of \\
edges. \\
\end{tabular} & \begin{tabular}{|l|} 
combine more \\
than on \\
technique, which \\
is take long time \\
process
\end{tabular} & $\begin{array}{l}\text { PSNR, RMSE, } \\
\text { SSIM }\end{array}$ & $\begin{array}{l}\text { the uncompressed } \\
\text { noisy image has } \\
\text { processed by SRAD } \\
\text { filter, then log is } \\
\text { performed on the } \\
\text { filtered image to } \\
\text { convert speckle } \\
\text { noise to Gaussian } \\
\text { noise. While DWT } \\
\text { using Bayesian } \\
\text { thresholding has } \\
\text { been done on the } \\
\text { log compressed } \\
\text { image to obtain } \\
\text { denoising image. }\end{array}$ \\
\hline $\begin{array}{l}(\underline{\text { Qian 2018) }} \\
{[20]}\end{array}$ & \begin{tabular}{|l|} 
A single \\
denoising \\
method \\
cannot \\
achieve \\
good effect \\
of \\
removing \\
those \\
mixed \\
noises such \\
as salt- and- \\
pepper \\
noise, \\
Gaussian \\
noise and \\
speckle \\
noise from \\
images.
\end{tabular} & \begin{tabular}{|l|} 
Mix noise \\
such as \\
Gaussian \\
noise, \\
salt-and- \\
pepper \\
noise and \\
speckle \\
noise
\end{tabular} & $\begin{array}{l}\text { Improved } \\
\text { wavelet } \\
\text { threshold } \\
\text { function and } \\
\text { median } \\
\text { filtering. }\end{array}$ & $\begin{array}{l}\text { effectively } \\
\text { eliminate } \\
\text { mixed noise, } \\
\text { that it can } \\
\text { get better } \\
\text { visual effect, } \\
\text { less loss of } \\
\text { detail } \\
\text { information } \\
\text {. also dealing } \\
\text { with } \\
\text { fingerprint } \\
\text { images and } \\
\text { printed circuit } \\
\text { board (PCB) } \\
\text { Images in } \\
\text { complex noise } \\
\text { environment. }\end{array}$ & \begin{tabular}{|l|} 
Mixed noise \\
request more than \\
on filter to reduce \\
noise as well, \\
using median \\
filter not effect \\
well when dialing \\
with another \\
noise
\end{tabular} & PSNR & $\begin{array}{l}\text { Improve threshold } \\
\text { function is } \\
\text { designed, which is } \\
\text { constructed to } \\
\text { avoid the defects of } \\
\text { hard } \\
\text { Threshold and soft } \\
\text { threshold. It is not } \\
\text { only continuous } \\
\text { and } \\
\text { derivable, but also } \\
\text { has less } \\
\text { compression of } \\
\text { wavelet } \\
\text { coefficients, which } \\
\text { solves the } \\
\text { oscillation and } \\
\text { boundary } \\
\text { Fuzziness to a } \\
\text { certain degree after } \\
\text { reconstruction. }\end{array}$ \\
\hline $\begin{array}{l}\left(\begin{array}{l}\text { Longkume } \\
\text { r and Gupta }\end{array}\right. \\
\underline{\text { 2018) [21] }}\end{array}$ & \begin{tabular}{|l|} 
Remove \\
noise \\
while it \\
preserves \\
the \\
importan \\
$\mathrm{t}$ \\
elements \\
of the \\
image.
\end{tabular} & \begin{tabular}{|l} 
Gaussia \\
n, Salt \\
and \\
Pepper \\
noise
\end{tabular} & $\begin{array}{l}\text { discrete } \\
\text { wavelet } \\
\text { transform } \\
\text { using Soft } \\
\text { Thresholdi } \\
\text { ng and } \\
\text { Wiener } \\
\text { Filter }\end{array}$ & $\begin{array}{l}\text { remove } \\
\text { noise while } \\
\text { it preserves } \\
\text { edge and } \\
\text { details }\end{array}$ & \begin{tabular}{|l|} 
Denoising \\
image \\
dependent on \\
Detail \\
coefficients \\
which is based \\
on db4 \\
wavelet only
\end{tabular} & PSNR, MSE & $\begin{array}{l}\text { Discrete wavelet } \\
\text { transform } \\
\text { applied on the } \\
\text { input image } \\
\text { Wiener Filter } \\
\text { aoolied on the } \\
\text { Approximation } \\
\text { coefficient and } \\
\text { perform Soft } \\
\text { Thresholding } \\
\text { applied on the } \\
\text { Detail } \\
\text { coefficients. }\end{array}$ \\
\hline
\end{tabular}




\begin{tabular}{|c|c|c|c|c|c|c|c|}
\hline $\begin{array}{l}(\underline{\text { Aghabalaei et }} \\
\text { al. 2018) [22] }\end{array}$ & $\begin{array}{l}\text { reducing } \\
\text { the speckle } \\
\text { noise from } \\
\text { time series } \\
\text { SAR } \\
\text { images to } \\
\text { preserve } \\
\text { the spatial } \\
\text { resolution } \\
\text { as well }\end{array}$ & $\begin{array}{l}\text { Speckle } \\
\text { noise }\end{array}$ & \begin{tabular}{|l} 
wavelet \\
transform \\
and Kalman \\
filter
\end{tabular} & $\begin{array}{l}\text { Reduce the } \\
\text { speckle noise } \\
\text { and its } \\
\text { effectiveness } \\
\text { to preserving } \\
\text { the edge } \\
\text { structures as } \\
\text { well as it } \\
\text { reduces the } \\
\text { time of } \\
\text { processing. }\end{array}$ & $\begin{array}{l}\text { Only provide } \\
\text { Synthetic } \\
\text { Aperture Radar } \\
\text { (SAR) imaging } \\
\text { systems }\end{array}$ & ENL, EEI & $\begin{array}{l}\text { all } \\
\text { of the images were } \\
\text { co-registered with } \\
\text { respect to one of the } \\
\text { Images, and then } \\
\text { the resampling } \\
\text { process was } \\
\text { performed. } \\
\text { Secondly, the first } \\
\text { image was de- } \\
\text { speckled using the } \\
\text { biorthogonal spline } \\
\text { wavelet and Birge- } \\
\text { Massart strategy. }\end{array}$ \\
\hline$\frac{(\text { Choi and }}{\text { Jeong 2018) }}$ & $\begin{array}{l}\text { edge } \\
\text { information } \\
\text { loss when } \\
\text { removing } \\
\text { speckle } \\
\text { noise in } \\
\text { SAR } \\
\text { images }\end{array}$ & $\begin{array}{l}\text { Speckle } \\
\text { noise }\end{array}$ & $\begin{array}{l}\text { soft } \\
\text { thresholding } \\
\text { and a guided } \\
\text { filter }\end{array}$ & $\begin{array}{l}\text { remove such } \\
\text { difficulties by } \\
\text { eliminating } \\
\text { the speckle } \\
\text { noise while } \\
\text { avoiding the } \\
\text { loss of edge } \\
\text { information } \\
\text { and critical } \\
\text { features }\end{array}$ & $\begin{array}{l}\text { Only provide } \\
\text { Synthetic } \\
\text { Aperture Radar } \\
\text { (SAR) imaging } \\
\text { systems }\end{array}$ & $\begin{array}{l}\text { RMSE,ENL, } \\
\text { PSNR and } \\
\text { SSIM }\end{array}$ & $\begin{array}{l}\text { SRAD filter used as } \\
\text { preprocessing filter } \\
\text { to preserve the } \\
\text { useful information } \\
\text { in the image of } \\
\text { noisy images, a } \\
\text { logarithmic } \\
\text { transformation } \\
\text { (Log) is applied to } \\
\text { convert speckle } \\
\text { noise are remaining } \\
\text { in the filtered image } \\
\text { into additive noise, } \\
\text { while guided filter } \\
\text { and soft } \\
\text { thresholding were } \\
\text { used to remove the } \\
\text { noise in the } \\
\text { approximation sub- } \\
\text { image (high- } \\
\text { frequency, low- } \\
\text { frequency). }\end{array}$ \\
\hline $\begin{array}{l}(\underline{\text { Dass 2018) }}) \\
{[24]}\end{array}$ & $\begin{array}{l}\text { Speckle } \\
\text { noise } \\
\text { degrades } \\
\text { the visual } \\
\text { evaluation } \\
\text { of } \\
\text { ultrasound } \\
\text { images. So } \\
\text { the main } \\
\text { challenge of } \\
\text { not } \\
\text { speckling is } \\
\text { to preserve } \\
\text { all the fine } \\
\text { details and } \\
\text { the edges of } \\
\text { the ultra- } \\
\text { sonographi } \\
\text { c images }\end{array}$ & $\begin{array}{l}\text { speckle } \\
\text { noise }\end{array}$ & $\begin{array}{l}\text { bacterial } \\
\text { foraging } \\
\text { optimization } \\
\text { (BFO) } \\
\text { cascaded } \\
\text { with wavelet } \\
\text { transformati } \\
\text { on and } \\
\text { wiener filter }\end{array}$ & \begin{tabular}{|l|} 
gives \\
recognizable \\
and acceptable \\
restoration of \\
ultrasound \\
images in \\
presence of \\
speckle noise
\end{tabular} & $\begin{array}{l}\text { Cover only } \\
\text { medical images }\end{array}$ & PSNR, MAE & $\begin{array}{l}\text { The wavelet packet } \\
\text { decomposition is } \\
\text { used to identify and } \\
\text { remove the noise } \\
\text { from affected pixels. } \\
\text { For pre-processing } \\
\text { purposes, the } \\
\text { Wiener filter is used } \\
\text { and BFO algorithm } \\
\text { is used to reduce } \\
\text { the amount of error } \\
\text { between the } \\
\text { speckled image and } \\
\text { the not speckled } \\
\text { output image from } \\
\text { the homomorphic } \\
\text { framework after } \\
\text { processing }\end{array}$ \\
\hline
\end{tabular}




\begin{tabular}{|c|c|c|c|c|c|c|c|}
\hline $\begin{array}{l}\frac{(\text { Tayade and }}{\text { Bhosale 2018) }} \\
{[25]}\end{array}$ & $\begin{array}{l}\text { Wavelet } \\
\text { techniques } \\
\text { are } \\
\text { effective to } \\
\text { remove the } \\
\text { noise due } \\
\text { to their } \\
\text { ability to } \\
\text { capture the } \\
\text { energy of a } \\
\text { signal in a } \\
\text { few energy } \\
\text { transform } \\
\text { values. } \\
\end{array}$ & $\begin{array}{l}\text { Not } \\
\text { specific }\end{array}$ & \begin{tabular}{|l} 
dual-tree \\
complex \\
wavelet and \\
Wiener filter
\end{tabular} & $\begin{array}{l}\text { enhancement } \\
\text { of the } \\
\text { resolution of a } \\
\text { low-resolution } \\
\text { medical image }\end{array}$ & $\begin{array}{l}\text { only medical } \\
\text { images Covered } \\
\text { and more } \\
\text { complex }\end{array}$ & $\begin{array}{l}\text { PSNR, SSIM, } \\
\text { and MSE }\end{array}$ & $\begin{array}{l}\text { DTCWT cascaded } \\
\text { structure used to } \\
\text { generate different } \\
\text { frequency bands for } \\
\text { analysis, while } \\
\text { denoising approach } \\
\text { for image is used } \\
\text { based on dual-tree } \\
\text { complex wavelet } \\
\text { and wiener filter } \\
\text { technique }\end{array}$ \\
\hline$\frac{(\text { Luo et al. }}{\frac{2018)}{[26]}}$ & $\begin{array}{l}\text { Improves } \\
\text { the } \\
\text { performanc } \\
\text { e of DWT } \\
\text { with } \\
\text { important } \\
\text { properties: } \\
\text { direction } \\
\text { selectivity } \\
\text { and nearly } \\
\text { shift } \\
\text { invariant. }\end{array}$ & $\begin{array}{l}\text { Not } \\
\text { specific }\end{array}$ & \begin{tabular}{|l|} 
double \\
density dual- \\
tree complex \\
wavelet \\
transform \\
$(\mathrm{DDCWT})$
\end{tabular} & $\begin{array}{l}\text { It obtains } \\
\text { direction } \\
\text { selectivity in } \\
\text { higher } \\
\text { dimensions } \\
\text { and nearly } \\
\text { shift invariant. }\end{array}$ & $\begin{array}{l}\text { Highly complex } \\
\text { and get more time } \\
\text { process }\end{array}$ & PSNR, MSE & $\begin{array}{l}\text { They used DDCWT } \\
\text { decompose noisy } \\
\text { CT image into high } \\
\text { frequency and low } \\
\text { frequency } \\
\text { components. In the } \\
\text { next, a modified } \\
\text { threshold is used } \\
\text { for DDCWT } \\
\text { coefficient. Finally, } \\
\text { the denoised } \\
\text { image is obtained } \\
\text { by reconstructing } \\
\text { high frequency and } \\
\text { low } \\
\text { frequency } \\
\text { components } \\
\text { through inverse } \\
\text { decomposition of } \\
\text { DDCWT. }\end{array}$ \\
\hline $\begin{array}{l}\text { (Kannan 2017) } \\
\text { [27] }\end{array}$ & $\begin{array}{l}\text { remove the } \\
\text { noise while } \\
\text { preserving } \\
\text { the edges } \\
\text { and details } \\
\text { in the } \\
\text { images } \\
\text { who } \\
\text { effected by } \\
\text { Gaussian } \\
\text { noise }\end{array}$ & $\begin{array}{l}\text { additive } \\
\text { white } \\
\text { Gaussian } \\
\text { noise }\end{array}$ & \begin{tabular}{|l|} 
wiener filter \\
and its \\
method noise \\
thresholding \\
using \\
discrete \\
wavelet \\
transform
\end{tabular} & $\begin{array}{l}\text { achieves much } \\
\text { better } \\
\text { performance } \\
\text { in removing } \\
\text { the additive } \\
\text { white } \\
\text { Gaussian noise } \\
\text { from the } \\
\text { image with } \\
\text { minimum } \\
\text { edge blurring } \\
\text { compared } \\
\text { with the } \\
\text { original } \\
\text { wiener filter }\end{array}$ & $\begin{array}{l}\text { Only efficient on } \\
\text { image who } \\
\text { contain the } \\
\text { additive white } \\
\text { Gaussian noise }\end{array}$ & $\begin{array}{l}\text { RMSE, PSNR, } \\
\text { QI }\end{array}$ & $\begin{array}{l}\text { Wiener filter is } \\
\text { often assumed to be } \\
\text { unsuitable for } \\
\text { images containing } \\
\text { edges and details, } \\
\text { while to deal with } \\
\text { edges and details in } \\
\text { images, the method } \\
\text { noise thresholding } \\
\text { used discrete } \\
\text { wavelet transform. }\end{array}$ \\
\hline
\end{tabular}




\begin{tabular}{|c|c|c|c|c|c|c|c|}
\hline $\begin{array}{l}\frac{\text { Chithra and }}{\text { Santhanam }} \\
\text { 2017) [28] }\end{array}$ & $\begin{array}{l}\text { suppressin } \\
\text { g the } \\
\text { Gaussian } \\
\text { noise from } \\
\text { CT images } \\
\text { in order to } \\
\text { improve } \\
\text { the quality } \\
\text { of the } \\
\text { images for } \\
\text { better } \\
\text { disease } \\
\text { diagnosing. }\end{array}$ & $\begin{array}{l}\text { Gaussian } \\
\text { noise }\end{array}$ & $\begin{array}{l}\text { Modified } \\
\text { Median } \\
\text { Wiener filter } \\
\text { (MMWF) } \\
\text { and Absolute } \\
\text { Difference } \\
\text { and Mean } \\
\text { filter } \\
\text { (ADMF). }\end{array}$ & \begin{tabular}{|l} 
remove \\
speckle noise \\
from the \\
Ultrasound \\
images to \\
preserve edge
\end{tabular} & \begin{tabular}{|l|} 
Cover only \\
medical image \\
which is effected \\
by Gaussian noise
\end{tabular} & PSNR, MSE & $\begin{array}{l}\text { MMWF used to } \\
\text { remove Gaussian } \\
\text { noise in the image. } \\
\text { This MMWF } \\
\text { merges the } \\
\text { complementary } \\
\text { qualities and } \\
\text { abilities of Median } \\
\text { (MF) and } \\
\text { Wiener Filter (WF). } \\
\text { While ADMF used } \\
\text { to remove speckle } \\
\text { noise from the } \\
\text { Ultrasound } \\
\text { images). An } \\
\text { attempt is made to } \\
\text { test whether this } \\
\text { filter is used to } \\
\text { remove Gaussian } \\
\text { noise from the } \\
\text { image. }\end{array}$ \\
\hline $\begin{array}{l}\text { (Ramadhan et } \\
\text { al. 2017) [29] }\end{array}$ & $\begin{array}{l}\text { choose a } \\
\text { suitable } \\
\text { image de- } \\
\text { noising } \\
\text { method to } \\
\text { restored } \\
\text { details of } \\
\text { an image } \\
\text { with noise }\end{array}$ & $\begin{array}{l}\text { Gaussian } \\
\text { noise }\end{array}$ & $\begin{array}{l}\text { median filter } \\
\text { (MF) and } \\
\text { DWT }\end{array}$ & $\begin{array}{l}\text { Has ability to } \\
\text { recover much } \\
\text { more detail of } \\
\text { the original } \\
\text { image. }\end{array}$ & $\begin{array}{l}\text { efficient for one } \\
\text { type of noise }\end{array}$ & MSE, PSNR & $\begin{array}{l}\text { median filter used } \\
\text { to remove Gaussian } \\
\text { noise from noisy } \\
\text { scaled image to } \\
\text { blurring and } \\
\text { smoothing edges } \\
\text { and details, while } \\
\text { the wavelet } \\
\text { transform applied } \\
\text { to analyze image }\end{array}$ \\
\hline $\begin{array}{l}\text { (Majeeth and } \\
\frac{\text { Babu 2017) }}{[30]}\end{array}$ & $\begin{array}{l}\text { removes } \\
\text { noise in an } \\
\text { image } \\
\text { while } \\
\text { preserves } \\
\text { the edges }\end{array}$ & $\begin{array}{l}\text { Gaussian } \\
\text { noise }\end{array}$ & $\begin{array}{l}\text { bilateral filter } \\
\text { and its } \\
\text { method noise } \\
\text { thresholding } \\
\text { based on the } \\
\text { dual-tree } \\
\text { complex } \\
\text { wavelet } \\
\text { transform }\end{array}$ & $\begin{array}{l}\text { give high } \\
\text { directional } \\
\text { selectivity and } \\
\text { perfect } \\
\text { reconstruction } \\
\text { of the edges } \\
\text { and other } \\
\text { essential } \\
\text { details of an } \\
\text { image which } \\
\text { are preserved }\end{array}$ & $\begin{array}{l}\text { Using specific } \\
\text { filter to remove } \\
\text { just specific type } \\
\text { of noise }\end{array}$ & $\begin{array}{l}\text { PSNR, SSIM, } \\
\text { UIQI }\end{array}$ & $\begin{array}{l}\text { bilateral filter } \\
\text { removes the noise } \\
\text { as well as some } \\
\text { details of the image, } \\
\text { so these details are } \\
\text { estimated } \\
\text { accurately in the } \\
\text { wavelet domain } \\
\text { with MMSE so that } \\
\text { the edges and other } \\
\text { features of the } \\
\text { original image are } \\
\text { preserved properly, } \\
\text { while the sum of } \\
\text { the bilateral filter } \\
\text { output and the } \\
\text { detail image will } \\
\text { give the final } \\
\text { denoised image. }\end{array}$ \\
\hline
\end{tabular}




\begin{tabular}{|c|c|c|c|c|c|c|c|}
\hline$\left(\begin{array}{l}\frac{\text { Wang et al. }}{2016)} \\
{[31]}\end{array}\right.$ & $\begin{array}{l}\text { use a large } \\
\text { window } \\
\text { size lead to } \\
\text { degrades } \\
\text { the image } \\
\text { detail }\end{array}$ & $\begin{array}{l}\text { Gaussian } \\
\text { noise }\end{array}$ & $\begin{array}{l}\text { wiener filter } \\
\text { with a high- } \\
\text { resolution } \\
\text { estimation }\end{array}$ & $\begin{array}{l}\text { Determines } \\
\text { and provide } \\
\text { the signal } \\
\text { power to } \\
\text { preserving the } \\
\text { edge } \\
\text { information }\end{array}$ & $\begin{array}{l}\text { Suitable for small } \\
\text { or specific } \\
\text { window size of } \\
\text { image }\end{array}$ & PSNR & $\begin{array}{l}\text { the local covariance } \\
\text { is used to get high- } \\
\text { resolution } \\
\text { coefficients from } \\
\text { coefficients with } \\
\text { low resolution } \\
\text { while to estimate } \\
\text { the signal variance } \\
\text { in the wiener filter } \\
\text { the high-resolution } \\
\text { values are used }\end{array}$ \\
\hline $\begin{array}{l}\text { Ismael et al. } \\
\text { 2016) [32] }\end{array}$ & $\begin{array}{l}\text { Enhance } \\
\text { the image } \\
\text { quality } \\
\text { after } \\
\text { degraded } \\
\text { by the } \\
\text { noise. }\end{array}$ & $\begin{array}{l}\text { Gaussian } \\
\text { Noise }\end{array}$ & $\begin{array}{l}\text { DWT and } \\
\text { MF }\end{array}$ & $\begin{array}{l}\text { Provide } \\
\text { clearly image } \\
\text { to preserve } \\
\text { edge and } \\
\text { details }\end{array}$ & $\begin{array}{l}\text { Deal with specific } \\
\text { amount of the } \\
\text { standard } \\
\text { deviation of } \\
\text { original images. }\end{array}$ & MSE, PSNR & $\begin{array}{l}\text { Wavelet transform } \\
\text { is used to analysis } \\
\text { the image due to } \\
\text { the ability to split } \\
\text { the image into sub- } \\
\text { bands and work on } \\
\text { each sub-band } \\
\text { frequencies } \\
\text { separately. While, } \\
\text { the RME has been } \\
\text { used to estimate the } \\
\text { noise ratio at the } \\
\text { noisy image. }\end{array}$ \\
\hline \begin{tabular}{|l}
$\frac{\text { Diwakar and }}{\text { Kumar 2016) }}$ \\
{$[33]$}
\end{tabular} & $\begin{array}{l}\text { When the } \\
\text { radiation } \\
\text { dose is low, } \\
\text { the quality } \\
\text { of CT } \\
\text { image is } \\
\text { degraded } \\
\text { in terms of } \\
\text { noise. } \\
\text { Therefore, } \\
\text { improve } \\
\text { the quality } \\
\text { of noisy CT } \\
\text { images, it } \\
\text { can be } \\
\text { helpful to } \\
\text { avoid the } \\
\text { need of } \\
\text { higher dose } \\
\text { CT images. }\end{array}$ & $\begin{array}{l}\text { Gaussian } \\
\text { noise }\end{array}$ & $\begin{array}{l}\text { DWT and } \\
\text { WF }\end{array}$ & $\begin{array}{l}\text { Provide edge } \\
\text { extraction to } \\
\text { improve the } \\
\text { quality of } \\
\text { denoised CT } \\
\text { images } \\
\text { through } \\
\text { discrete } \\
\text { wavelet } \\
\text { transformation } \\
\text { (DWT) with } \\
\text { respect to } \\
\text { noise } \\
\text { suppression } \\
\text { and structure } \\
\text { preservation. }\end{array}$ & $\begin{array}{l}\text { Does not provide } \\
\text { all CT } \\
\text { reconstructed } \\
\text { images. }\end{array}$ & PSNR, SSIM & $\begin{array}{l}\text { Two intermediate } \\
\text { result are obtained } \\
\text { the first } \\
\text { intermediate result } \\
\text { is subtracted from } \\
\text { the input noisy } \\
\text { image and } \\
\text { processed using } \\
\text { wavelet packet } \\
\text { thresholding. The } \\
\text { outcome of wavelet } \\
\text { packet thresholding } \\
\text { is second } \\
\text { intermediate result. } \\
\text { Both intermediate } \\
\text { results are added to } \\
\text { gain the final } \\
\text { denoised CT image. }\end{array}$ \\
\hline
\end{tabular}




\begin{tabular}{|c|c|c|c|c|c|c|c|}
\hline$\frac{\text { (Diwakar and }}{\text { Kumar 2016) }}$ & $\begin{array}{l}\text { When the } \\
\text { radiation } \\
\text { dose is low, } \\
\text { the quality } \\
\text { of CT } \\
\text { image is } \\
\text { degraded } \\
\text { in terms of } \\
\text { noise. } \\
\text { Therefore, } \\
\text { improve } \\
\text { the quality } \\
\text { of noisy CT } \\
\text { images, it } \\
\text { can be } \\
\text { helpful to } \\
\text { avoid the } \\
\text { need of } \\
\text { higher dose } \\
\text { CT images. }\end{array}$ & $\begin{array}{l}\text { Gaussian } \\
\text { noise }\end{array}$ & $\begin{array}{l}\text { DWT and } \\
\text { WF }\end{array}$ & $\begin{array}{l}\text { Provide edge } \\
\text { extraction to } \\
\text { improve the } \\
\text { quality of } \\
\text { denoised CT } \\
\text { images } \\
\text { through } \\
\text { discrete } \\
\text { wavelet } \\
\text { transformation } \\
\text { (DWT) with } \\
\text { respect to } \\
\text { noise } \\
\text { suppression } \\
\text { and structure } \\
\text { preservation. }\end{array}$ & $\begin{array}{l}\text { Does not provide } \\
\text { all CT } \\
\text { reconstructed } \\
\text { images. }\end{array}$ & PSNR, SSIM & $\begin{array}{l}\text { Two intermediate } \\
\text { result are obtained } \\
\text { the first } \\
\text { intermediate result } \\
\text { is subtracted from } \\
\text { the input noisy } \\
\text { image and } \\
\text { processed using } \\
\text { wavelet packet } \\
\text { thresholding. The } \\
\text { outcome of wavelet } \\
\text { packet thresholding } \\
\text { is second } \\
\text { intermediate result. } \\
\text { Both intermediate } \\
\text { results are added to } \\
\text { gain the final } \\
\text { denoised CT image. }\end{array}$ \\
\hline $\begin{array}{l}\text { (Mohan et al. } \\
\underline{\text { 2016) }} \text { [34] }\end{array}$ & \begin{tabular}{|l|} 
Reduce the \\
speckle \\
noise \\
without \\
sacrificing \\
the \\
information \\
content.
\end{tabular} & $\begin{array}{l}\text { speckle } \\
\text { noise }\end{array}$ & $\begin{array}{l}\text { wiener } \\
\text { filtering and } \\
\text { adaptive soft } \\
\text { thresholding }\end{array}$ & $\begin{array}{l}\text { Has ability to } \\
\text { significantly } \\
\text { reduce the } \\
\text { speckle noise }\end{array}$ & $\begin{array}{l}\text { Only cover (SAR) } \\
\text { field }\end{array}$ & PSNR, MSE & $\begin{array}{l}\text { Wiener filter used } \\
\text { as a preprocessing } \\
\text { stage in the spatial } \\
\text { domain and } \\
\text { adaptive soft } \\
\text { thresholding of } \\
\text { Wavelet transform } \\
\text { coefficients used in } \\
\text { the frequency } \\
\text { domain }\end{array}$ \\
\hline $\begin{array}{l}\frac{\text { Saluja and }}{\text { Boyat 2015) }} \\
{[35]}\end{array}$ & \begin{tabular}{|l} 
How to \\
remove the \\
noise from \\
the \\
corrupted \\
image as \\
well as \\
preserve \\
the edges \\
and other \\
detailed \\
features
\end{tabular} & $\begin{array}{l}\text { Add } \\
\text { additive } \\
\text { white } \\
\text { Gaussian }\end{array}$ & $\begin{array}{l}\text { WHFC and } \\
\text { Adaptive } \\
\text { Wiener filter }\end{array}$ & $\begin{array}{l}\text { Remove the } \\
\text { noise from the } \\
\text { noisy image } \\
\text { which gives } \\
\text { better visual } \\
\text { appearance. }\end{array}$ & $\begin{array}{l}\text { Consider only } \\
\text { Gaussian noise }\end{array}$ & PSNR & $\begin{array}{l}\text { Apply WHFC on } \\
\text { the detailed parts to } \\
\text { increased intensity } \\
\text { of the pixels. Then, } \\
\text { they convolved } \\
\text { WHFC with } \\
\text { detailed coefficients } \\
\text { of wavelet. The } \\
\text { resultant image was } \\
\text { obtained during } \\
\text { inverse wavelet } \\
\text { transform process, } \\
\text { while the resultant } \\
\text { image is visually } \\
\text { blurred. Adaptive } \\
\text { Wiener filter used } \\
\text { to minimize the } \\
\text { blurriness of the } \\
\text { resultant image }\end{array}$ \\
\hline $\begin{array}{l}\text { (Naimi et al. } \\
\text { 2015) [36] }\end{array}$ & \begin{tabular}{|l} 
enhanceme \\
nt the \\
discrete \\
wavelet \\
transform \\
with \\
important \\
additional \\
properties \\
to preserve \\
the edges \\
and details \\
of noisy \\
image
\end{tabular} & & $\begin{array}{l}\text { dual-tree } \\
\text { complex } \\
\text { wavelet and } \\
\text { shrinkage } \\
\text { with the } \\
\text { Wiener filter }\end{array}$ & $\begin{array}{l}\text { Improve better } \\
\text { balance of } \\
\text { smoothness } \\
\text { and accuracy } \\
\text { than the DWT } \\
\text { and are less } \\
\text { redundant } \\
\text { than the SWT }\end{array}$ & $\begin{array}{l}\text { Applied only for } \\
\text { medical image } \\
\text { using only db4' } \\
\text { family wavelets. }\end{array}$ & PSNR, SSIM & $\begin{array}{l}\text { They estimate the } \\
\text { noise level and then } \\
\text { for DWT, SWT and } \\
\text { DTCWT based } \\
\text { denoising they used } \\
\text { 'db4' family } \\
\text { wavelets. }\end{array}$ \\
\hline
\end{tabular}




\section{Conclusion}

Many techniques based on wavelet transform hybrid with some spatial domain filters such as Wiener filter, Median filter, anisotropic filter, bilateral filter and etc., have been implemented to preserve details and edges of the image as much as possible. Therefore, this work present a reviewed approaches of image denoising of various methodologies which adopted to obtain the optimum image denoising performance. The above survey of different type of methods, show that some of them depended on using the primary WT (DWT), and some of them depending on complex WT (DTCWT) using filters to remove single or mixed type (multiplicative) of noise (Gaussian noise, and saltpepper, speckle) in noisy image to obtain denoising image that to be close to original image as much as possible depending on various threshold techniques (universal thresholding, soft thresholding, hard thresholding, Bayesian thresholding). Different traditional and new measurement parameters have been used to evaluate methods.

These various methods still lag behind in the better visual quality of the image. More performance parameters can be calculate to study the behavior of the hybrid techniques by making a good compromise in various noise reduction fields. A better hybrid technique with a suitable filter model can be designed to remove single and mixed noise in multiple images in all areas gives a better visual appearance, without destitution the details of the image and take into account the processing time of the denoising image.

\section{References}

1. Kommineni, V.R.R. and H.K. Kalluri, Image Denoising Techniques. International Journal of Recent Technology and Engineering (IJRTE), 2019. 7(5S4).

2. Koranga, P., et al., Image Denoising Based on Wavelet Transform using Visu Thresholding Technique. International
Journal of Mathematical, Engineering and Management Sciences, 2018.

3. Singh, L. and R. Janghel, Harmony Search and Nature Inspired Optimization Algorithms "Image Denoising Techniques: A Brief Survey". Advances in Intelligent Systems and Computing 741, springer, 2018. 731-740.

4. Alisha, P.B. and G.S. K, Image Denoising Techniques-An Overview. Journal of Electronics and Communication Engineering (IOSR-JECE), 2016. 11(1): p. 78-84.

5. Fan, L., et al., Brief review of image denoising techniques. Springer Singapore (Visual Computing for Industry, Biomedicine, and Art), 2019.

6. Song, Q., et al., Image Denoising Based on Mean Filter and Wavelet Transform. IEEE 4th International Conference on Advanced Information Technology and Sensor Application (AITS), 2015.

7. Wang, G., Z. Wang, and J. Liu, A New Image Denoising Method Based on Adaptive Multiscale Morphological Edge Detection. Mathematical Problems in Engineering, 2017.

8. Xiaoa, F. and Y. Zhanga, A Comparative Study on Thresholding Methods in Waveletbased Image Denoising. Elsevier (Advanced in Control Engineeringand Information Science), 2011. 15.

9. Kethwas, A. and B. Jharia, Image de-noising using Fuzzy and Wiener filter in Wavelet domain. IEEE International Conference on Electrical, Computer and Communication Technologies (ICECCT), 2015.

10. Jagadesh, T. and R.J. Rani, A novel speckle noise reduction in biomedical images using PCA and wavelet transform. IEEE International Conference on Wireless Communications, Signal Processing and Networking (WiSPNET), 2016.

11. Agarwal, S.K. and P. Kumar, Denoising of A Mixed Noise Color Image Through Special Filter. International Journal of Signal Processing, Image Processing and Pattern Recognition, 2016. 9(1): p. 159-176.

12. Kaur, G. and R. Kaur, Image De-Noising Using Wavelet Transform and Various Filters. International Journal of Research in Computer Science, 2012. 2(2): p. 15-21. 
13. Kumar, P. and S.K. Agarwal, A Color Image Denoising By Hybrid Filter for Mixed Noise. International Journal of Current Engineering and Technology (ijcet), 2015. 5 .

14. Lin, L., An Effective Denoising Method for Images Contaminated with Mixed Noise Based on Adaptive Median Filtering and Wavelet Threshold Denoising. J Inf Process Syst (JIPS), 2017. 14(2): p. 539-551.

15. Fan, L., et al., Brief review of image denoising techniques. Visual Computing for Industry, Biomedicine, and Art, 2019.

16. Guhathakurta, R., Denoising of Image : A Wavelet Based Approach. 8th Annual Industrial Automation and Electromechanical Engineering Conference (IEMECON), 2017.

17. Chen, B., et al., Adaptive Wavelet Filter With Edge Compensation for Remote Sensing Image Denoising. IEEE, 2019. 7: p. 91966 - 91979.

18. Qian, Y., Removing of Salt-and-pepper Noise in Images Based on Adaptive Median Filtering and Improved Threshold Function. 2019 Chinese Control And Decision Conference (CCDC), 2019.

19. Nishu, I.Z., et al., A New Image Despeckling Method by SRAD Filter and Wavelet Transform Using Bayesian Threshold. IEEE International Conference on Electrical, Computer and Communication Engineering (ECCE), 2019.

20. Qian, Y., Image Denoising Algorithm Based on Improved Wavelet Threshold Function and Median Filter. IEEE 18th International Conference on Communication Technology (ICCT), 2018.

21. Longkumer, M. and H. Gupta, Denoising of Images Using Wavelet Transform,Weiner Filter and Soft Thresholding. International Research Journal of Engineering and Technology (IRJET), 2018. 5(6).

22. Aghabalaei, A., et al., Speckle Noise Reduction of Time Series SAR Images Based On Wavelet Transform and Kalman Filter. IGARSS 2018 - IEEE International Geoscience and Remote Sensing Symposium, 2018.

23. Choi, H. and J. Jeong, Despeckling Images Using a Preprocessing Filter and Discrete Wavelet Transform-Based
Noise Reduction Techniques. IEEE Sensors Journal 2018. 18(8): p. 3131 - 3139.

24. Dass, R., Speckle Noise Reduction of Ultrasound Images Using BFO Cascaded with Wiener Filter and Discrete Wavelet Transform in Homomorphic Region. Procedia Computer Science, International Conference on Computational Intelligence and Data Science (ICCIDS 2018). 2018. 132: p. 1543-1551.

25. Tayade, P.M. and S.P. Bhosale, Medical Image Denoising and Enhancement using DTCWT and Wiener filter. International Journal of Advance Research, Ideas and Innovations in Technology (IJARIIT), 2018. 4(4).

26. Luo, P., et al., CT Image Denoising Using Double Density Dual Tree Complex Wavelet with Modified Thresholding. IEEE 2nd International Conference on Data Science and Business Analytics (ICDSBA), 2018.

27. Kannan, K., A New Hybrid Image Denoising Algorithm Based on Wiener Filter and Wavelet Thresholding. International Journal of Research in Information Technology, 2017. 1(2): p. 37-45.

28. Chithra, K. and T. Santhanam, Hybrid Denoising Technique for Suppressing Gaussian Noise in Medical Images. IEEE International Conference on Power, Control, Signals and Instrumentation Engineering (ICPCSI), 2017.

29. Ramadhan, A., F. Mahmood, and A. Elci, Image Denoising by Median Filter In Wavelet Domain. The International Journal of Multimedia \& Its Applications (IJMA), 2017. 9(1).

30. Majeeth, S.S. and C.N.K. Babu, A Novel Algorithm to Remove Gaussian Noise in an Image. IEEE International Conference on Computational Intelligence and Computing Research (ICCIC), 2017.

31. Wang, J., et al., Wiener filter-based wavelet domain denoising. Elsevier - Displays, 2016. 46: p. 37-41.

32. Ismael, S.H., D.F.M. Mustafa, and D.İ.T. OKÜMÜŞ, A New Approach of Image Denoising Based on Discrete Wavelet Transform. IEEE World Symposium on Computer Applications \& Research, 2016.

33. Diwakar, M. and M. Kumar, Edge Preservation Based CT Image Denoising Using Wiener Filtering and Thresholding in Wavelet Domain. IEEE Fourth International Conference 
on Parallel, Distributed and Grid Computing (PDGC),

2016.

34. Mohan, R., S. Mridula, and P. Mohanan, Speckle Noise Reduction in Images using WienerFiltering and Adaptive Wavelet Thresholding. IEEE Region 10 Conference (TENCON), 2016.

35. Saluja, R. and A. Boyat, Wavelet based Image Denoising using Weighted Highpass Filtering Coefficients and Adaptive Wiener Filter. IEEE International Conference on Computer, Communication and Control (IC4-2015), 2015.

36. Naimi, H., et al., Medical image denoising using dual tree complex thresholding wavelet transform and Wiener filter. Journal of King Saud University - Computer and Information Sciences, 2015. 